\title{
Children's takeaway and fast-food intakes: associations with the neighbourhood food environment
}

\author{
Anna F Timperio, Kylie Ball, Rebecca Roberts, Nick Andrianopoulos and \\ David A Crawford* \\ Centre for Physical Activity and Nutrition Research, School of Exercise and Nutrition Sciences, Deakin University, \\ 221 Burwood Highway, Melbourne, Victoria 3125, Australia
}

Submitted 22 July 2008: Accepted 11 December 2008: First published online 26 February 2009

\begin{abstract}
Objective: The present study aimed to examine associations between availability of outlets where takeaway or fast food could be purchased and consumption of takeaway or fast food among children.

Design: Cross-sectional. Parents completed a questionnaire regarding the frequency per week their child usually ate takeaway or fast foods. The availability of outlets where these foods could be purchased close to home and en route to school was determined with a Geographic Information System (presence of any outlets and density of outlets within $800 \mathrm{~m}$ from home and along the route to school, and distance from home to closest outlet).

Setting: Greater Melbourne and Geelong, Australia.

Subjects: Three hundred and fifty-three children aged 5-6 years and 463 children aged 10-12 years.

Results: Overall, $69 \cdot 4 \%$ of children consumed takeaway or fast foods once weekly or more often. Only one measure of availability of outlets close to home was associated with consumption; each additional outlet within $800 \mathrm{~m}$ was associated with 3\% lower odds of consuming takeaway or fast foods at least once weekly $(\mathrm{OR}=0 \cdot 97,95 \%$ CI $0 \cdot 95,1 \cdot 00)$. There were no associations between availability en route to school and the likelihood of consuming takeaway or fast food at least once weekly.

Conclusions: Access to outlets where takeaway or fast food could be purchased did not predict frequency of consumption of takeaway or fast food in the expected direction. Such relationships appear to be complex and may not be adequately captured by the measures of access included in the current study.
\end{abstract}

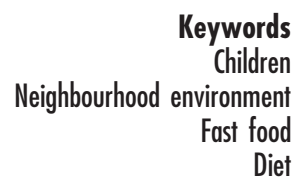

There is widespread concern about the rapidly increasing prevalence of childhood obesity in Western countries ${ }^{(1)}$. Obesity is the result of sustained energy imbalance and epidemiological evidence suggests that specific eating behaviours contribute to high-energy and high-fat diets. Eating fast food is one such eating behaviour that is becoming more common among children ${ }^{(2)}$; it has been associated with weight gain among adults ${ }^{(3-5)}$ and with poorer dietary profiles, such as higher total energy, percentage energy from fat and soft drink intake and lower consumption of fruit and vegetables, among children ${ }^{(6,7)}$, adolescents $^{(8)}$ and adults ${ }^{(7)}$. Although changing the neighbourhood fast-food environment has been suggested as a potential strategy for improving dietary behaviours ${ }^{(9)}$, surprisingly little empirical research has examined environmental correlates of eating behaviours ${ }^{(10)}$.

Several studies have examined how the availability of different types of food stores, such as fast-food outlets, convenience stores and out-of-home eating outlets, varies across geographic areas of differing socio-economic status (SES), with mixed results ${ }^{(11-19)}$. However, few studies have examined whether exposure to such outlets is associated with greater consumption of takeaway or fast food. The little existing research shows no association between adiposity and availability of fast-food outlets among children ${ }^{(20-22)}$ and mixed evidence among adults $^{(23-25)}$. The notion that availability of food outlets may influence dietary behaviours has merit, however, since there is some evidence that children with greater availability of fast-food outlets and convenience stores close to home are less likely to consume recommended amounts of fruit and vegetables ${ }^{(26)}$. The aim of the present study was to examine associations between availability of outlets where takeaway or fast food can be purchased close to home and along the route to school and regular consumption of these foods among children. 


\section{Methods}

Parents of children aged 5-6 and 10-12 years in Melbourne and Geelong, Australia, completed questionnaires about their child's eating behaviours in 2002 or 2003. These data were combined with data extracted from a geographic information system (GIS) in 2004-5. Survey data collection was approved by the Deakin University Ethics Committee, the Department of Education and Training Victoria and the Catholic Education Office.

\section{Sample}

Parents of children in grade prep (primary school entry grade, 5-6 years) and grades 5 and 6 (final primary school grades, 10-12 years) were recruited from twenty-four primary schools which had enrolments of greater than 200 students $^{(27)}$. These state and Catholic schools were randomly sampled from the Greater Melbourne and Geelong areas from postcodes with high, medium and low SES ${ }^{(28)}$. Recruitment procedures have been reported elsewhere ${ }^{(27)}$. Briefly, of the 3695 children provided with invitational materials about the study to take home to their parents, 1560 (42\%) provided active consent and took part. Only children for whom data were available regarding their residential address and frequency of consumption of takeaway or fast food were included in the analyses (343 children aged 5-6 years and 463 aged 10-12 years).

\section{Measures}

\section{Sociodemographic variables}

The questionnaire administered to parents requested details of parent's marital status, the highest level of maternal education (collapsed into three categories: low, did not complete high school; medium, high school or technical or trade certificate; high, university or tertiary qualification), maternal employment and whether English was usually spoken at home.

\section{Neighbourbood socio-economic status}

For each child, neighbourhood SES was determined at the postcode level using the Socio-Economic Index For Areas (SEIFA) Index of Relative Socio-Economic Advantage/ Disadvantage ${ }^{(28)}$. Higher scores on this index reflect a more advantaged area. Neighbourhoods were stratified into SES tertiles.

\section{Takeaway or fast food consumption}

Parents were asked how frequently per week their child usually ate takeaway or fast foods (e.g. pizza, hamburgers and chips) at home and away from home. In Australia, 'takeaway' food typically refers to full meals purchased from fast-food outlets, restaurants, cafés and takeaway stores (e.g. fish and chip shops), but taken home or elsewhere to eat or home-delivered for immediate consumption. Six response options were provided: never or rarely; less than once weekly; once weekly; about 2-3 times weekly; about 4-6 times weekly; every day. Frequencies of takeaway and fast food consumption at home or away from home were combined and dichotomised as less than once weekly and at least once weekly to indicate regular consumption. Test-retest reliability of the dichotomised variable among a subset of thirty-eight parents who were administered these questions on two occasions 2-3 weeks apart was excellent (85\% agreement).

\section{Context of fast food or takeaway consumption}

Parents were asked how frequently they or a co-carer ate takeaway or fast food with their child at home or away from home, took their child to a fast-food restaurant and provided money to their child to buy snacks, treats or fast food. Response options were identical to those previously described and each item was dichotomised as less than once weekly $v$. at least once weekly.

\section{Access to food outlets}

The availability of food outlets where takeaway or fast foods could be purchased was determined using the GIS software ArcView 3.3 and relevant extensions (ESRI, Redlands, CA, USA). Outlets where takeaway or fast foods could be purchased included fast-food chain outlets, cafés, restaurants, takeaway stores and convenience stores, and their physical addresses were obtained from food premises registers kept by local government, electronic databases (including telephone directories and company websites) and online and printed dining guides. The locations of the food outlets, residential addresses of participants and the school attended were geo-coded and overlaid with the road network (VicMap Transport v2004; owned and supplied by the State of Victoria).

Consistent with previous work ${ }^{(26)}$, three measures of availability from home were computed: (i) distance to the closest outlet along the shortest possible route; (ii) number of outlets within a $800 \mathrm{~m}$ road network buffer (i.e. within a walking distance); and (iii) existence of any outlet within the $800 \mathrm{~m}$ network buffer ( 0 outlets; $\geq 1$ outlet). In addition, the shortest possible route to school along the road network was identified for each participant and two measures of availability along the route were computed: (i) number of outlets along the route (operationalised as within $50 \mathrm{~m}$ either side of the road centreline); and (ii) access to any outlets along the route (0 outlets; $\geq 1$ outlet).

\section{Statistical analyses}

Statistical analyses were performed using the STATA statistical software package version $8 \cdot 0$ (Stata Corporation, College Station, TX, USA). Regular consumption of takeaway or fast food was compared by sex within age group, and by age group within sex, using Pearson's $\chi^{2}$ tests. Consumption of takeaway or fast food and availability of outlets were compared according to neighbourhood SES 
using independent $t$ tests or Pearson's $\chi^{2}$ tests. Separate logistic regression analyses were performed to predict regular consumption of takeaway or fast food using each measure of availability of outlets as independent variables (unadjusted models). Each model was repeated adjusting for neighbourhood-level SES (adjusted models). All regression models controlled for potential clustering according to the sampling unit (school attended) using the CLUSTER command and were also repeated stratified by age group.

\section{Results}

\section{Sample profile}

Similar proportions of boys and girls participated (Table 1). Most parents were married or living as married (de facto relationship) and most families usually spoke English at home. Maternal education was skewed towards medium to higher levels of education and just over $40 \%$ of female carers had full- or part-time paid employment.

\section{Takeaway or fast food consumption}

Overall, $69 \cdot 4 \%$ of children regularly consumed takeaway or fast food. There were no differences in the proportion of

Table 1 Profile of studied families of 5-6- and 10-12-year-old children, greater Melbourne and Geelong, Australia

\begin{tabular}{lc}
\hline & Overall (\%) \\
\hline Sex (male) & $49 \cdot 1$ \\
Age group (5-6 years) & $42 \cdot 6$ \\
Marital status & \\
$\quad$ Married/de facto (living together) & $83 \cdot 0$ \\
Separated, divorced or widowed & $13 \cdot 5$ \\
Never married & $3 \cdot 5$ \\
Maternal education & $22 \cdot 3$ \\
$\quad$ Low & $38 \cdot 6$ \\
Medium & $39 \cdot 1$ \\
High & \\
Maternal employment & $15 \cdot 2$ \\
Full-time paid employment & $27 \cdot 2$ \\
Part-time paid employment & $57 \cdot 6$ \\
Other & $88 \cdot 6$ \\
Usually speak English at home & \\
\hline
\end{tabular}

children consuming takeaway or fast food according to sex among either age group, according to age group among boys or girls, nor according to neighbourhood SES.

Overall, $62 \cdot 4 \%$ of children ate takeaway or fast food with a parent or co-carer at least once weekly, $18 \cdot 7 \%$ took their child to fast-food restaurants at least once weekly and $39.7 \%$ of parents or co-carers provided money to their child to buy snacks, treats or fast food.

\section{Availability of food stores close to bome and en route to school}

On average, the closest outlet from home where fast food or takeaway could be purchased was $0.7(\mathrm{SD} 0.5) \mathrm{km}$ away and children had access to an average of $4 \cdot 0$ (SD $5 \cdot 9$ ) outlets within $800 \mathrm{~m}$ of home and $2 \cdot 1$ (SD $6 \cdot 1$ ) en route to school. Over two-thirds (69.6\%) of children had at least one outlet within $800 \mathrm{~m}$ of home and $40 \cdot 8 \%$ at least one en route to school. There were differences in availability according to neighbourhood SES (Table 2).

\section{Associations between availability of food stores and consumption of takeaway or fast foods}

The results of logistic regression analyses predicting consumption of takeaway or fast food are shown in Table 3. Only density of stores close to home was associated with consuming takeaway or fast food at least once weekly; however, this association was borderline and in a negative direction. When analyses were stratified by age group, this association was found only among older children (OR $=0 \cdot 9,95 \%$ CI $0 \cdot 8,0 \cdot 9, P=0 \cdot 003)$. Older children with at least one outlet close to home were also less likely to consume takeaway or fast food regularly (OR $=0 \cdot 7,95 \%$ CI $0 \cdot 5,0 \cdot 9, P=0 \cdot 016)$.

\section{Discussion}

It has been suggested that changing the neighbourhood fast-food environment, while likely to be difficult, could potentially have a large impact on dietary behaviours ${ }^{(9)}$. However, the present study did not find associations in

Table 2 Availability of stores/outlets where takeaway or fast food can be purchased close to home and en route to school for 5-6- and 10-12-year-old children, greater Melbourne and Geelong, Australia

\begin{tabular}{|c|c|c|c|c|c|c|}
\hline & \multicolumn{6}{|c|}{ SES category } \\
\hline & \multicolumn{2}{|c|}{ Low (n 268) } & \multicolumn{2}{|c|}{ Medium ( $n$ 255) } & \multicolumn{2}{|c|}{ High (n 282) } \\
\hline & Mean & SD & Mean & SD & Mean & SD \\
\hline \multicolumn{7}{|l|}{ Access from home } \\
\hline Distance $(\mathrm{km})$ to closest & $0 \cdot 6^{\mathrm{a}}$ & 0.4 & $0 \cdot 8^{\mathrm{b}}$ & 0.7 & $0 \cdot 7^{\mathrm{b}}$ & 0.5 \\
\hline Number within $800 \mathrm{~m}$ & $4 \cdot 3^{a}$ & $5 \cdot 6$ & $2 \cdot 5^{\mathrm{b}}$ & 3.9 & $5 \cdot 2^{\mathrm{a}}$ & $7 \cdot 8$ \\
\hline Any $(\geq 1)$ within $800 \mathrm{~m}(\%)$ & \multicolumn{2}{|c|}{$77 \cdot 6$} & \multicolumn{2}{|c|}{$60 \cdot 4$} & \multicolumn{2}{|c|}{$70 \cdot 2^{*}$} \\
\hline Access along route to school & & & & & & \\
\hline Number along route & $1 \cdot 2^{\mathrm{a}}$ & $2 \cdot 4$ & $1 \cdot 5^{\mathrm{a}}$ & $3 \cdot 3$ & $3 \cdot 5^{\mathrm{b}}$ & $9 \cdot 4$ \\
\hline Any $(\geq 1)$ along route $(\%)$ & \multicolumn{2}{|c|}{$36 \cdot 6$} & \multicolumn{2}{|c|}{$45 \cdot 5$} & \multicolumn{2}{|c|}{$40 \cdot 4$} \\
\hline
\end{tabular}

SES, socio-economic status.

${ }_{\mathrm{a}, \mathrm{b}}$ Mean values within a row with unlike superscript letters were significantly different (one-way ANOVA with Sheffé post hoc tests): $P<0.05$.

${ }^{*} \chi^{2}$ test of significance: $P<0 \cdot 001$. 
Table 3 Associations between availability of stores where takeaway or fast food can be purchased and consumption of takeaway or fast food for 5-6- and 10-12-year-old children, greater Melbourne and Geelong, Australia

\begin{tabular}{|c|c|c|c|c|}
\hline & \multicolumn{4}{|c|}{ Consume takeaway or fast food at least once weekly } \\
\hline & \multicolumn{2}{|c|}{ Crude analysist } & \multicolumn{2}{|c|}{ Adjusted analysisł } \\
\hline & OR & $95 \% \mathrm{Cl}$ & OR & $95 \% \mathrm{Cl}$ \\
\hline \multicolumn{5}{|l|}{ Access from home } \\
\hline Distance $(\mathrm{km})$ to closest & $1 \cdot 2$ & $0.9,1.5$ & $1 \cdot 2$ & $0.9,1.5$ \\
\hline Number within $800 \mathrm{~m}$ & $0.98^{*}$ & $0.96,0.995$ & $0.98^{*}$ & $0.95,0.999$ \\
\hline Any $(\geq 1)$ within $800 \mathrm{~m}$ & $0 \cdot 8$ & $0 \cdot 6,1 \cdot 1$ & $0 \cdot 8$ & $0 \cdot 6,1 \cdot 1$ \\
\hline \multicolumn{5}{|l|}{ Access along route to school } \\
\hline Number along route & $1 \cdot 0$ & $1 \cdot 0,1 \cdot 0$ & $1 \cdot 0$ & $1 \cdot 0,1 \cdot 0$ \\
\hline Any $(\geq 1)$ along route & $1 \cdot 2$ & $0.9,1 \cdot 7$ & $1 \cdot 2$ & $0.9,1.5$ \\
\hline
\end{tabular}

*Significant association: $P<0 \cdot 05$.

tAdjusted only for clustering by school.

¥Adjusted for neighbourhood-level socio-economic status and clustering by school.

the expected direction between availability of outlets where takeaway or fast food could be purchased close to home or along a frequently travelled route and regular takeaway or fast food consumption among children. Regardless of the neighbourhood environment, our findings show that parents are likely to play an important role in regulating children's access to outlets where takeaway and fast food can be purchased. In the present study, $62 \%$ of participants usually ate takeaway or fast food with a parent, and 19\% were usually taken to a fastfood restaurant by a parent every week. Thus, parents are likely to be important mediators of consumption of takeaway and fast food.

Results related to outlet availability and SES were mixed. Children living in low-SES areas were more likely to have an outlet of this type within $800 \mathrm{~m}$ and to live closer to one such outlet, but had a similar number of outlets available compared with children living in highSES areas. However, children living in high-SES areas had more than twice as many outlets where takeaway or fast food could be purchased en route to school than did children in low- or medium-SES areas. These conflicting results may reflect the types of land uses permitted and the nature of the street network in the neighbourhoods studied. For example, Macintyre et al. ${ }^{(16)}$ found few outof-home eating outlets located in primarily residential areas and suggested that such outlets are more likely to be located where they would receive the highest level of exposure. Consistent with this view, two US studies have found that fast food ${ }^{(29,30)}$ and snack $^{(30)}$ outlets are concentrated around schools. While the current study is unique in considering the potential impact of repeated exposure along a route frequently travelled by children (to school), no associations with consumption were found.

The use of objective measures of the neighbourhood food environment unique to each participant rather than at the area level and the use of multiple sources to identify outlets are strengths of the present study. However, the study was cross-sectional and, although reliable, the validity (particularly for older children) of parent reports of their child's behaviour is unknown. It is also not known how long participants had lived at their address or how long each outlet had been trading. Since the locations of food outlets were sourced during the two years following the survey (2004 and 2005), it is possible that some outlets may have opened or closed in the interim. In addition, specific menu options at each outlet included in the study were not gathered; thus, restaurants or cafés that did not offer takeaway or fast food could not be excluded. Further, although our sample did not differ from the original sample according to sociodemographics and takeaway or fast food consumption, the subset included a greater proportion of children with high maternal education than the original sample $(39 \cdot 1 \%$ v. 32.8\%).

The present study suggests that exposure to outlets where takeaway or fast food can be purchased close to home or en route to school is not associated with the frequency children consume these types of food. The findings may also help to explain null findings of previous research examining relationships between availability of fast-food outlets and obesity among children ${ }^{(20-22)}$. Future research should examine other types of eating behaviours and could include older children or adolescents who may have more autonomy to visit or buy food from such stores.

\section{Acknowledgements}

Survey data collection was funded by the Victorian Health Promotion Foundation, and collection and geo-coding of data related to locations of food outlets was funded in part by the State of Victoria through its Department of Human Services (DHS). The views and conclusions are those of the authors and do not necessarily represent those of DHS. A.F.T. and D.A.C. were supported by Public Health Research Fellowships from the Victorian Health Promotion Foundation. K.B. was supported by a National Health and Medical Research Council Senior Research Fellowship. There are no conflicts of interest. A.F.T. and K.B. designed and A.F.T. oversaw the food environment 
component of the study. R.R. performed all spatial analyses and N.A. and A.F.T. conducted statistical analyses. D.A.C. conceived and oversaw the collection of the survey component of the study. A.F.T. drafted the manuscript and all authors helped interpret results and provided critical feedback. The authors wish to thank Dr Michelle Jackson, Sophie Thal-Janzen, Jackie Newman, Anne Savige and Kate Udorovich, David Attard and Dr Remy Sietchiping for their assistance in survey or spatial data collection, and Kellie Horton from DHS for comments on a draft.

\section{References}

1. Lobstein $\mathrm{T}$, Baur L \& Uauy R, for the IASO International Obesity TaskForce (2004) Obesity in children and young people: a crisis in public health. Obes Rev 5, 4-85.

2. St-Onge M-P, Keller KL \& Heymsfield SB (2003) Changes in childhood food consumption patterns: a cause for concern in light of increasing body weights. Am J Clin Nutr $\mathbf{7 8}$, 1068-1073.

3. Duffey KJ, Gordon-Larsen P, Jacobs DR, Williams D \& Popkin BM (2007) Differential associations of fast food and restaurant food consumption with 3-y change in body mass index: the Coronary Artery Risk Development in Young Adults Study. Am J Clin Nutr 85, 201-208.

4. Bowman SA \& Vinyard BT (2004) Fast food consumption of US adults: impact on energy and nutrient intakes and overweight status. J Am Coll Nutr 23, 163-168.

5. Ball K, Brown W \& Crawford D (2002) Who does not gain weight? Prevalence and predictors of weight maintenance in young women. Int J Obes Relat Metab Disord 26, $1570-1578$.

6. Bowman SA, Gortmaker SL, Ebbeling CB, Pereira MA \& Ludwig DS (2004) Effects of fast-food consumption on energy intake and diet quality among children in a National Household Survey. Pediatrics 113, 112-118.

7. Paeratakul S, Ferdinand DP, Champagne CM, Ryan DH \& Bray GA (2003) Fast-food consumption among US adults and children: dietary and nutrient intake profile. J Am Diet Assoc 103, 1332-1338.

8. French SA, Story M, Neumark-Sztainer D, Fulkerson JA \& Hannan P (2001) Fast food restaurant use among adolescents: associations with nutrient intake, food choices and behavioral and psychosocial variables. Int $J$ Obes Relat Metab Disord 25, 1823-1833.

9. Booth SL, Sallis JF, Ritenbaugh C et al. (2001) Environmental and societal factors affect food choice and physical activity: rationale, influences and leverage points. Nutr Rev 59, Suppl., S21-S39.

10. Ball K, Timperio AF \& Crawford DA (2006) Understanding environmental influences on nutrition and physical activity behaviors: where should we look and what should we count? Int J Behav Nutr Phys Act 3, 33.

11. Reidpath DD, Burns C, Garrard J, Mahoney M \& Townsend M (2002) An ecological study of the relationship between social and environmental determinants of obesity. Health Place 8, 141-145.

12. Block JP, Scribner RA \& DeSalvo KB (2004) Fast food, race/ ethnicity, and income. A geographic analysis. Am J Prev Med 27, 211-217.
13. Pearce J, Blakely T, Witten K \& Bartie P (2007) Neighborhood deprivation and access to fast-food retailing. $A m \mathrm{~J}$ Prev Med 32, 375-382.

14. Winkler E, Turrell G \& Patterson P (2006) Does living in a disadvantaged area mean fewer opportunities to purchase fresh fruit and vegetables in the area? Findings from the Brisbane food study. Health Place 12, 306-319.

15. Morland K, Wing S, Diez Roux A \& Poole C (2001) Neighborhood characteristics associated with the location of food stores and food service places. Am J Prev Med 22, 23-29.

16. Macintyre S, McKay L, Cummins S \& Burns C (2005) Out-ofhome food outlets and area deprivation: case study in Glasgow, UK. Int J Behav Nutr Phys Act 2, 16.

17. Powell LM, Slater S, Mirtcheva D, Bao Y \& Chaloupka FJ (2007) Food store availability and neighborhood characteristics in the United States. Prev Med 44, 189-195.

18. Horowitz CR, Colson KA, Hebert PL \& Lancaster K (2004) Barriers to buying healthy foods for people with diabetes: evidence of environmental disparities. Am J Public Health 94, 1549-1554.

19. Macdonald L, Cummins S \& Macintyre S (2007) Neighbourhood fast food environment and area deprivation substitution or concentration? Appetite 49, 251-254.

20. Burdette HL \& Whitaker RC (2003) Neighborhood playgrounds, fast food restaurants, and crime: relationships to overweight in low-income preschool children. Prev Med 38, 57-63.

21. Crawford DA, Timperio AF, Salmon JA, Baur L, Giles-Corti B, Roberts RJ, Jackson ML \& Ball K (2008) Neighbourhood fast food outlets and obesity in children and adults: the CLAN Study. Int J Pediatr Obes 3, 249-256.

22. Sturm R \& Datar A (2005) Body mass index in elementary school children, metropolitan area food prices and food outlet density. Public Health 119, 1059-1068.

23. Simmons D, McKenzie A, Eaton S, Cox N, Khan MA, Shaw J \& Zimmet P (2005) Choice and availability of takeaway and restaurant food is not related to the prevalence of adult obesity in rural communities in Australia. Int J Obes (Lond) 29, 703-710.

24. Maddock J (2004) The relationship between obesity and the prevalence of fast food restaurants: state-level analysis. Am J Health Promot 19, 137-143.

25. Jeffery RW, Baxter JE, McGuire MT \& Linde JA (2006) Are fast food restaurants an environmental risk factor for obesity? Int J Behav Nutr Phys Act 3, 2.

26. Timperio A, Ball K, Roberts R, Campbell K, Andrianopoulos N \& Crawford D (2008) Children's fruit and vegetable intake: associations with the neighbourhood food environment. Prev Med 46, 331-335.

27. Salmon J, Campbell KJ \& Crawford DA (2006) Television viewing habits associated with obesity risk factors: a survey of Melbourne schoolchildren. Med J Austr 184, 64-67.

28. Australian Bureau of Statistics (2003) Socio-Economic Indexes for Areas, 2001. Canberra: Australian Bureau of Statistics.

29. Austin SB, Melly SJ, Sanchez BN, Patel A, Buka S \& Gortmaker SL (2005) Clustering of fast-food restaurants around schools: a novel application of spatial statistics to the study of food environments. Am J Public Health 95 , 1575-1581.

30. Kipke MD, Iverson E, Moore D, Booker C, Ruelas V, Peters AL \& Kaufman F (2007) Food and park environments: neighborhood-level risks for childhood obesity in East Los Angeles. J Adolesc Health 40, 325-333. 